\title{
Evidence of Annealing Effects on a High-Density Si/ Si02 Interfacial Layer
}

\section{Citation}

Kosowsky, S. D., Peter S. Pershan, K. S. Krisch, J. Bevk, M. L. Green, D. Brasen, L. C. Feldman, and P. K. Roy. 1997. Evidence of annealing effects on a high-density Si/SiO2 interfacial layer. Applied Physics Letters 70(23): 3119-3121.

\section{Published Version}

doi:10.1063/1.119090

\section{Permanent link}

http://nrs.harvard.edu/urn-3:HUL.InstRepos:10357486

\section{Terms of Use}

This article was downloaded from Harvard University's DASH repository, and is made available under the terms and conditions applicable to Other Posted Material, as set forth at http:// nrs.harvard.edu/urn-3:HUL.InstRepos:dash.current.terms-of-use\#LAA

\section{Share Your Story}

The Harvard community has made this article openly available.

Please share how this access benefits you. Submit a story.

Accessibility 


\title{
Evidence of annealing effects on a high-density $\mathrm{Si} / \mathrm{SiO}_{2}$ interfacial layer
}

\author{
S. D. Kosowsky and P. S. Pershan \\ Harvard University, Cambridge, Massachusetts 02138 \\ K. S. Krisch, J. Bevk, M. L. Green, D. Brasen, and L. C. Feldman ${ }^{\text {a) }}$ \\ Bell Laboratories, Lucent Technologies, Murray Hill, New Jersey 07974 \\ P. K. Roy \\ Bell Laboratories, Lucent Technologies, Orlando, Florida 32819
}

(Received 17 April 1996; accepted for publication 9 April 1997)

\begin{abstract}
Thermally grown $\mathrm{Si}(001) / \mathrm{SiO}_{2}$ samples were studied by x-ray reflectivity. Fits of model electron density profiles to the data reveal the existence of an interfacial layer at the $\mathrm{Si} / \mathrm{SiO}_{2}$ interface up to 15 - $\AA$-thick, with density higher than either the crystalline $\mathrm{Si}$ or the main oxide layer. This density of the layer is reduced by a postoxidation anneal. (c) 1997 American Institute of Physics.

[S0003-6951(97)02823-4]
\end{abstract}

With the continual drive to scale down the dimensions of metal-oxide-semiconductor (MOS) devices, the structure of the silicon/silicon oxide interface is becoming increasingly important. It has long been expected that the interfacial 5-10 $\AA$ of $\mathrm{SiO}_{2}$ has anomalous characteristics. ${ }^{1-3}$ Current $0.35 \mu \mathrm{m}$ gate-length devices use 70-80- $\AA$-thick gate oxides, and for these devices, anomalies in the interfacial structures on the order of $5 \AA^{4,5}$ or larger ${ }^{6}$ are a significant fraction of the oxide and may affect device characteristics. ${ }^{6}$ Effects of interfacial microstructures on mobility degradation and oxide breakdown are expected to become increasingly important in the performance of these submicron devices. ${ }^{7}$ Nevertheless, the density profile for MOS structure has still not been fully determined.

Studies of the as-grown $\mathrm{Si} / \mathrm{SiO}_{2}$ interface have reported a layer at that interface, whose structure ${ }^{6,8-11}$ and stoichiometry ${ }^{1,12}$ differ from that of the surrounding crystalline $\mathrm{Si}$ and amorphous $\mathrm{SiO}_{2}$ regions. This interfacial oxide region has been shown to be Si-rich, compared to $\mathrm{SiO}_{2},{ }^{1,8,11,13}$ but the electron density profile there is still unknown. Furthermore, in the case of devices, it is important to know how this structure evolves with annealing, which, for example, has been shown to change the silicon oxide density. ${ }^{14}$ In this letter we report the electron density profiles extracted from $x$-ray reflectivity studies of thermally grown $\mathrm{Si}(001) / \mathrm{SiO}_{2}$ samples. These profiles contain the highdensity layer at the crystal/oxide interface that can be anticipated by some other studies of oxidized $\mathrm{Si}(001)$ surfaces. The extent of the layer depends on the growth environment, and the layer is affected by thermal annealing.

The oxides used in this study were grown via rapid thermal oxidation at $1000{ }^{\circ} \mathrm{C}$ for $10-200 \mathrm{~s}$ to create a range of oxide thicknesses. Three groups of samples were studied (see Table I). The first group, with thicknesses from about 50 to $300 \AA$, was formed in a 760 Torr $\mathrm{O}_{2}$ ambient, and the second group, with thicknesses $35-70 \AA$, in a 40 Torr $\mathrm{O}_{2}$ environment. Two of the samples from the first group were subsequently annealed and comprise group three. The anneals were done with a flow of prepurified Ar gas, at $1000{ }^{\circ} \mathrm{C}$ for $1 \mathrm{~h}$. X-ray data were taken on a two-circle spectrometer us-

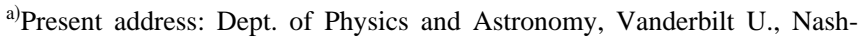
ville, TN 37235. ing a Rigaku rotating anode source of $\mathrm{Cu} K \alpha(\lambda=1.54 \AA)$ radiation and a $\mathrm{Ge}(111)$ monochromator to create a highly collimated, narrow beam.

The measured x-ray reflectivity $R(q)$ is essentially a Fourier transform of the spatial derivative of the sample density in the perpendicular $(z)$ direction, averaged over the lateral $(x, y)$ directions. Specifically, for $q \gtrsim q_{c}$, where $q$ is the wave vector transfer along the surface normal ${ }^{15}$

$$
\frac{R(q)}{R_{f}(q)}=\left|\frac{1}{\rho_{\mathrm{sub}}} \int \frac{d \rho(z)}{d z} e^{i q z} d z\right|^{2},
$$

where $R_{f}(q)$ is the Fresnel function for the bulk substrate, $q_{c}$ is the critical angle $\left(q_{c}=0.0316 \AA^{-1}\right)$, and $\rho_{\text {sub }}$ is the electron density well inside the bulk $\mathrm{Si}$ substrate $(2.33$ $\left.\mathrm{gm} / \mathrm{cm}^{3}\right) .{ }^{16}$ The data were actually analyzed using an exact formalism, ${ }^{17}$ valid even at the critical angle. However, for discussion, we present the kinematic approximation [Eq. (1)] to make the physics more transparent.

A typical reflectivity data set for an as-grown sample is shown along with fits in Fig. 1(a), with the corresponding real space models in Fig. 1(b). The $R / R_{f}$ falls below 1.0 at the smallest $q$ values because the incident beam does not fall entirely within the sample boundaries. To fit the data, we use a slab model with fitted parameters that represent the bulk substrate, the oxide overlayer (layer 2) and a dense interfacial layer (layer 1), where each layer above the bulk substrate is described by a density $\rho_{n}$ and a layer thickness $d_{n}$. This is the solid line in Figs. 1(a) and 1(b). Note that in Eq. (1), $R / R_{f}$ is sensitive to $\left(1 / \rho_{\text {sub }}\right) d \rho / d z$ (i.e., $\left.\rho_{n} / \rho_{\mathrm{Si}}-1\right)$, hence the sensitivity to small density differences among the layers. Two of the other real space models which were attempted, and which have fewer parameters, are shown as broken lines in Fig. 1(b), with the corresponding fits in Fig. 1(a). These models omit the dense interfacial layer $\left(d_{1} \equiv 0\right)$, and a visual inspection of the fits rules out both these models for the as-grown samples.

The x-ray data from sample 2, measured before and after annealing, are shown in Fig. 2 along with fits based on Eq. (1). The real space models producing these fits are shown in the inset. The pre and postanneal reflectivities both show oscillations in $q$, whose periods are functions of the oxide layer thicknesses, through Eq. (1). The change in the $R / R_{f}$ caused by annealing clearly demonstrates that the oxide 
TABLE I. Fitted model parameters for the slab model. The values of $\rho_{1}$ and $\rho_{2}$ are normalized by $\rho_{\mathrm{Si}}\left(2.33 \mathrm{gm} / \mathrm{cm}^{3}\right)$. The range of excess strength values are indicated in Fig. 3.

\begin{tabular}{|c|c|c|c|c|c|c|c|}
\hline & Sample & $d_{1}[\AA]$ & $d_{2}[\AA]$ & $\frac{\rho_{1}}{\rho_{\mathrm{Si}}}-1$ & $\rho_{2} / \rho_{\mathrm{Si}}$ & $\begin{array}{c}\text { Excess strength } \\
{[\AA]}\end{array}$ & $d_{\text {Ellipsometry }}[\AA]$ \\
\hline \multirow{6}{*}{$\begin{array}{l}760 \text { Torr } \mathrm{O}_{2} \\
\text { unannealed }\end{array}$} & 1 & $15.7 \pm 2.0$ & $272.6 \pm 0.8$ & $0.023 \pm 0.004$ & $0.984 \pm 0.004$ & 0.36 & 290 \\
\hline & 2 & $14.7 \pm 2.0$ & $138.9 \pm 0.9$ & $0.018 \pm 0.004$ & $0.981 \pm 0.004$ & 0.27 & 153 \\
\hline & 3 & $14.8 \pm 2.1$ & $101.2 \pm 1.0$ & $0.019 \pm 0.005$ & $0.980 \pm 0.004$ & 0.28 & 115 \\
\hline & 4 & $14.2 \pm 1.9$ & $70.2 \pm 0.9$ & $0.023 \pm 0.005$ & $0.990 \pm 0.004$ & 0.33 & 82.8 \\
\hline & 5 & $14.7 \pm 2.3$ & $59.7 \pm 1.2$ & $0.019 \pm 0.006$ & $0.977 \pm 0.004$ & 0.29 & 72.7 \\
\hline & 6 & $14.3 \pm 2.1$ & $40.0 \pm 1.3$ & $0.023 \pm 0.006$ & $0.991 \pm 0.004$ & 0.33 & 53.5 \\
\hline \multirow{3}{*}{$\begin{array}{l}40 \text { Torr } \mathrm{O}_{2} \\
\text { unannealed }\end{array}$} & 7 & $14.7 \pm 3.1$ & $55.4 \pm 1.4$ & $0.013 \pm 0.005$ & $0.987 \pm 0.004$ & 0.19 & 67.5 \\
\hline & 8 & $12.7 \pm 3.0$ & $41.0 \pm 1.1$ & $0.111 \pm 0.005$ & $0.980 \pm 0.004$ & 0.13 & 53.5 \\
\hline & 9 & $9.6 \pm 3.1$ & $25.3 \pm 1.1$ & $0.012 \pm 0.006$ & $0.989 \pm 0.004$ & 0.11 & 32.9 \\
\hline \multirow{2}{*}{$\begin{array}{l}760 \text { Torr } \mathrm{O}_{2} \\
\text { annealed }\end{array}$} & $2 \mathrm{a}$ & $8.7+6 /-8.7$ & $154.6 \pm 1.3$ & $0.001+0.008 /-0.001$ & $0.958 \pm 0.005$ & 0.01 & 166 \\
\hline & $4 a$ & $12.8 \pm 4.2$ & $87.6 \pm 1.2$ & $0.009 \pm 0.005$ & $0.968 \pm 0.003$ & 0.12 & 99.9 \\
\hline
\end{tabular}

overlayer has changed. However, the overall thickness of the oxide as determined through the x-ray scattering, $d_{1}+d_{2}$, corresponds well with ellipsometry data taken on these samples.

For all of the unannealed samples, grown either in 760 or 40 Torr $\mathrm{O}_{2}$ environments, the additional layer is required to produce a satisfactory fit to the measured data. A summary of the best fitted model parameters is found in Table I. Ideally, the interfacial widths, thicknesses, and densities of the model would be determined from fits to the data through Eq.
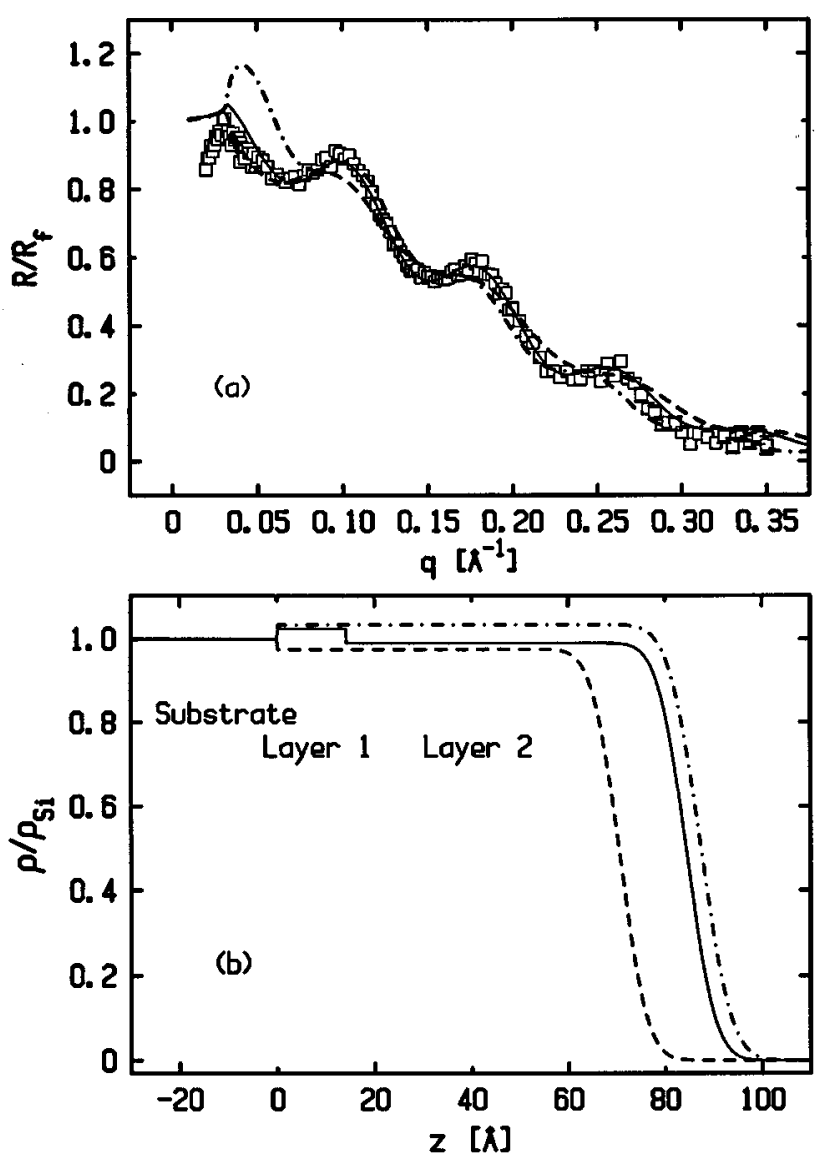

FIG. 1. (a) Typical x-ray reflectivity data ( $\square$ ) from an unannealed sample (sample 4), with fits corresponding to the real space models of (b). The single oxide layer models (broken lines) produce poor fits, whereas the two-layer model (solid line) fits the data well.
(1). The interfacial widths of the additional layer are set equal to 0 , since without large $q$ data, the fits are not sensitive to the detailed shape of the profile. Also given in the table is the product $d_{1}\left(\rho_{1} / \rho_{\mathrm{Si}}-1\right)$, which is the integrated electron density excess or "excess (scattering) strength," of the layer. It characterizes the extent of the dense, interfacial layer and, to first order, its importance to the x-ray scattering structure, since it is a leading term in the expansion of Eq. (1). Furthermore, in the fitting, small changes in the fitting parameter $d_{1}$ can be compensated by an opposite change in

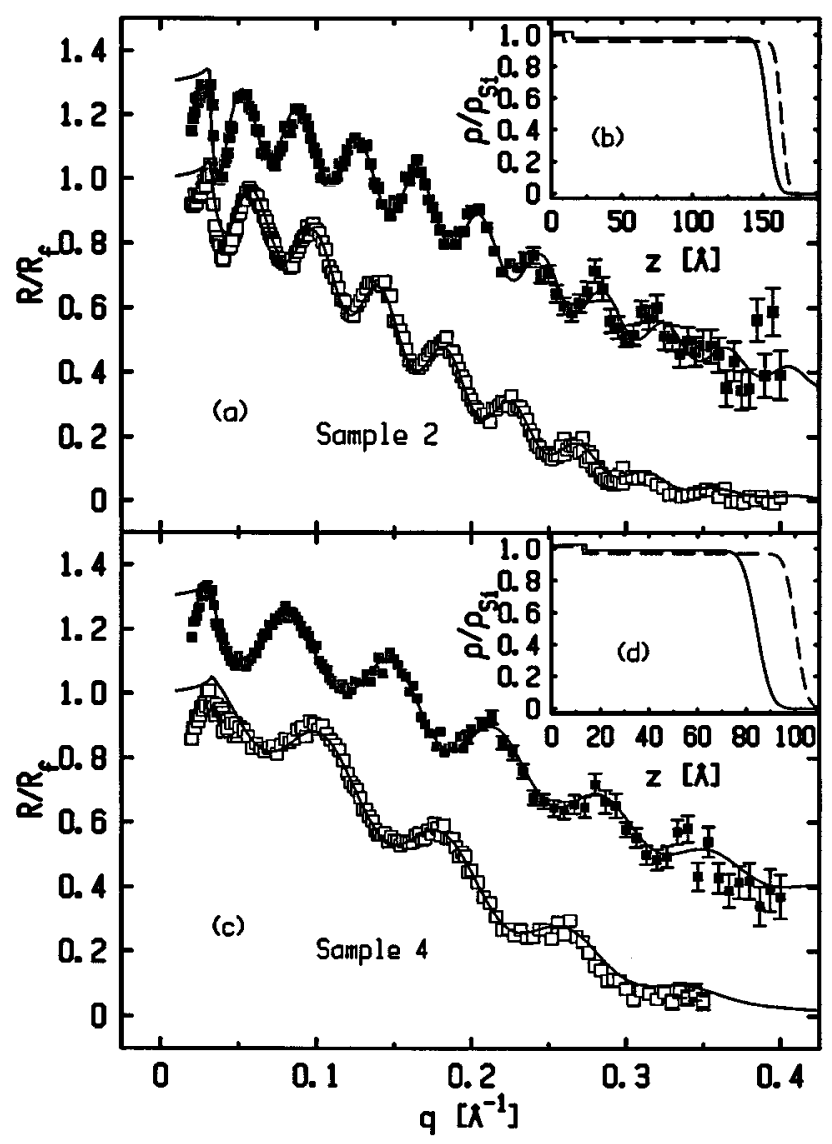

FIG. 2. (a) and (c) Comparison of the reflectivities before [( $\square$ ) samples 2, 4] and after [(耳) samples 2a, 4a] annealing. Annealing causes significant changes in the reflectivities, indicating significant changes in the samples. (b) and (d) Real space profiles producing fits in [(a) and (c), respectively]: unannealed (-) and annealed (----). 


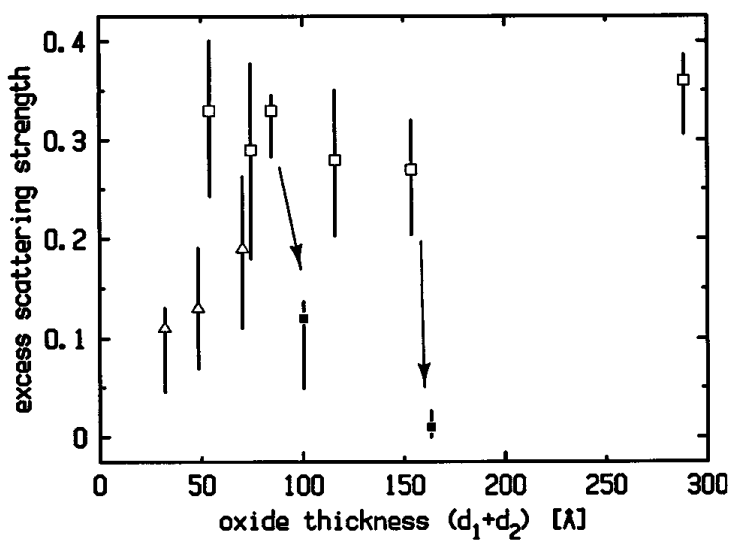

FIG. 3. Excess scattering strength $\left[d_{1}\left(\rho_{1} / \rho_{\mathrm{Si}}-1\right)\right]$ in the interfacial layer as a function of oxide thickness. ( $\square$ ) 760 Torr $\mathrm{O}_{2},(\triangle) 40$ Torr $\mathrm{O}_{2}$, ( $\boldsymbol{\square}$ ) annealed. The arrows indicate the change from before to after annealing.

the parameter $\rho_{1}$. Physical interpretation in terms of the excess scattering strength avoids uncertainties associated with this thickness-density interdependence.

The values for the excess strength deduced from the fits are displayed in Fig. 3 with the range indicated by the bars (the symbol identifies the group). The unannealed samples grown in a 760 Torr $\mathrm{O}_{2}$ environment have the largest values of excess strength, averaging about $0.3 \AA$. The excess strength values exhibit no thickness dependence over the range studied. The unannealed samples grown in 40 Torr $\mathrm{O}_{2}$ show a middle range of excess strength, around $0.1-0.2$ $\AA$. The annealed samples have excess densities of $<0.14 \AA$, half the unannealed values. In fact, the X-ray reflectivity data for the annealed samples can be reasonably well fit without any interfacial layer at all (zero excess density). This is presumably because the lower values of $\rho_{1}-\rho_{\mathrm{Si}}$ make the interface (and hence the layer) more transparent to X-rays. The ellipsometry thickness data, however, requires that the additional oxide be present, and so supports the small, but finite excess density values.

Theoretical studies of the oxidation of silicon have suggested the presence of an intermediate layer between the $\mathrm{Si}$ (001) and $\mathrm{SiO}_{2}{ }^{5,18,19}$ While the bulk of the oxide is a stable amorphous $\mathrm{SiO}_{2}$ layer, ${ }^{18}$ the region near the $\mathrm{Si}(001)$ interface may be a transition layer, possibly stabilized by high stresses which are known to exist within the oxides ${ }^{20,21}$ and especially at the $\mathrm{Si} / \mathrm{SiO}_{2}$ interface. ${ }^{14}$ Alternatively, the layer could be a region of higher density strained silicon, where the lattice is compressed slightly in the vertical. In either case, annealing, which is well known to reduce stresses, would affect the $\mathrm{Si} / \mathrm{SiO}_{2}$ interfacial structure. High-resolution core level spectroscopy studies on native oxides have shown that annealing shifts $\mathrm{Si} / \mathrm{SiO}_{2}$ spectra away from interfacial, substochiometric states towards higher $\mathrm{Si}^{+4}$ states. ${ }^{12}$ This is consistent with the annealing-induced reduction in excess strength of the interfacial layer reported here.

For the unannealed samples, the fitted density of the main oxide layer $\rho_{2}$ is independent of the oxide thickness and the $\mathrm{O}_{2}$ partial pressure during growth, and is unaffected by the layer 1 parameters. The density is affected by annealing, however, as the annealed samples show an average oxide density $\left(\rho_{2}\right)$ reduction of $2.3 \%$ as compared to the unan- nealed samples. Furthermore, the values of the main oxide density $\rho_{2}$ both annealed and unannealed agree well with values deduced indirectly through ellipsometry measurements of the index of refraction of thin thermally grown $\mathrm{SiO}_{2}$ films. ${ }^{14}$ Finally, we mention that the oxide-vacuum interface has a root mean square roughness of 3.5-5.1 $\AA$, in agreement with similar oxide measurements. ${ }^{15}$

In conclusion, we have used $\mathrm{x}$-ray reflectivity to probe the $\mathrm{Si} / \mathrm{SiO}_{2}$ interface, revealing an interfacial layer with density higher than either crystalline $\mathrm{Si}$ or the main oxide layer. Quantitative values obtained for the excess scattering strength, a measure of the extent of this layer, is a function of the $\mathrm{O}_{2}$ partial pressure of the growth environment in the as-grown oxide. Postoxidation annealing reduces the excess strength of this interfacial layer, and additionally reduces the density of the main oxide layer. This study could be extended to include wider ranges of ambient oxygen partial pressures as well as thicker oxides, to explore possible trends.

The authors thank K. Evans-Lutterodt, D. Monroe, and T. Sorsch for valuable discussions. One author (S.D.K.) gratefully acknowledges the support of Bell Laboratories, Lucent Technologies. This work was supported by Bell Laboratories, Lucent Technologies and by Harvard Materials Research Laboratory under Grant No. NSF-DMR-89-20490.

${ }^{1}$ F. J. Himpsel, F. R. McFeely, A. Taleb-Ibrahimi, and J. A. Yarmoff, Phys. Rev. B 38, 6084 (1988).

${ }^{2}$ A. Ourmazd, D. W. Taylor, J. A. Rentschler, and J. Bevk, Phys. Rev. Lett. 59, 213 (1987).

${ }^{3}$ F. Rochet, M. Froment, C. D'Anterroches, H. Roulet, and G. Dufour, Philos. Mag. B 59, 339 (1989).

${ }^{4}$ T. A. Rabedeau, I. M. Tidswell, P. S. Pershan, J. Bevk, and B. S. Freer, Appl. Phys. Lett. 59, 3422 (1993).

${ }^{5}$ A. M. Stoneham, C. R. M. Grovenor, and A. Cerezo, Philos. Mag. B 60, 189 (1989).

${ }^{6}$ E. Hasegawa, A. Ishitani, K. Akimoto, M. Tsukiji, and N. Ohta, J. Electrochem. Soc. 142, 273 (1995).

${ }^{7}$ T. Ohmi, M. Miyashita, M. Itano, T. Imaoka, and I. Kawanabe, IEEE Trans. Electron Devices 39, 537 (1992).

${ }^{8}$ E. Taft and L. Cordes, J. Electrochem. Soc. 126, 131 (1979).

${ }^{9}$ T. A. Rabedeau, I. M. Tidswell, P. S. Pershan, J. Bevk, and B. S. Freer, Appl. Phys. Lett. 59, 706 (1991).

${ }^{10}$ G. Renaud, P. H. Fuoss, A. Ourmazd, J. Bevk, and B. S. Freer, Appl. Phys. Lett. 59, 706 (1991).

${ }^{11}$ N. W. Cheung, L. C. Feldman, P. C. Silverman, and I. Stensgaard, Appl. Phys. Lett. 35, 859 (1979).

${ }^{12}$ F. J. Himpsel, D. A. Lapiano-Smith, J. F. Morar, and J. Bevk, Local Bonding at $\mathrm{SiO}_{2} /$ Siinterfaces (Electrochemical Society, New York, 1992).

${ }^{13}$ E. P. Gusev, H. C. Lu, T. Gustafsson, and E. Garfunkel, Phys. Rev. B 52, 1759 (1995).

${ }^{14}$ K. Taniguchi, M. Tanaka, C. Hamaguchi, and K. Imai, J. Appl. Phys. 67, 2195 (1990)

${ }^{15}$ I. M. Tidswell, B. M. Ocko, P. S. Pershan, S. R. Wasserman, G. M. Whitesides, and J. D. Axe, Phys. Rev. B 41, 111 (1990).

${ }^{16}$ The $\mathrm{x}$-ray data actually determine the electron density profile. However, for compounds of the light elements (such as $\mathrm{Si}$ and $\mathrm{O}$ ), electron density and mass density are proportional independent of composition to well within the error bars of this experiment.

${ }^{17}$ L. G. Parratt, Phys. Rev. 131, 359 (1954).

${ }^{18}$ C. J. Sofield and A. M. Stoneham, Semicond. Sci. Technol. 10, 215 (1995).

${ }^{19}$ I. Ohdomari, H. Akatsu, Y. Yamakoshi, and K. Kishimoto, J. Appl. Phys. 62, 3751 (1988).

${ }^{20}$ L. M. Landsberger and W. A. Tiller, Appl. Phys. Lett. 51, 1416 (1987).

${ }^{21}$ J. Fitch, G. Lucovsky, E. Kobeda, and E. Irene, J. Vac. Sci. Technol. B 7, 153 (1989). 